\title{
QUI... DADA C'EST MOI. Historia de un huevo, por MISE en PLIS. Libro/objeto en memoria a Emilio Sdun. QUI... DADA C'EST MOI. History of an egg, by MISE in PLIS. Book / Object in memory to Emilio Sdun.
}

\author{
Lourdes Santamaría Blasco (MISE en PLIS) \\ Facultad de BBAA, Universidad Miguel Hernández \\ de Elche, España. \\ msantamaria@umh.es
}

\section{Amparo Alepuz Rostoll (MISE en PLIS)}

Facultad de BBAA, Universidad Miguel Hernández de Elche, España.

a.alepuz@umh.es

\section{Rocio Villalonga Campos (MISE en PLIS)}

Facultad de BBAA, Universidad Miguel Hernández de Elche, España.

rociovillalonga@gmail.com
Recibido 30/11/2016

Aceptado 07/01/2017
Revisado 05/01/2017

Publicado 01/07/2017

\section{Resumen}

Tres artistas agrupadas bajo el nombre de MISE en PLIS, ponen en escena (mise en scene) una investigación y diseño sobre la producción, reproductibilidad, difusión y comercialización de obra artística, con una perspectiva interdisciplinar y trabajando en la edición del libro/objeto de artista, tanto como soporte de obras gráficas (ilustraciones, fotografías, collages) como contenedor de objetos siguiendo la tradición Dadaísta y Surrealista respecto a los objets trouvés y los ready mades. Las obras resultantes de esta investigación rinden homenaje a las estrategias creativas de estos movimientos de vanguardia, desde el concepto de lo fragmentado

\section{Abstract}

Three artists grouped under the name of MISE in PLIS, staged (mise en scene) research and design on production, reproducibility, diffusion and commercialization of artistic work with an interdisciplinary perspective and working on the edition of the book / object artist, both as a support of graphic works (illustrations, photographs, co-llages) as container objects following the Dadaist and Surrealist tradition regarding the found objects and readymades. The works resulting from this research pay tribute to

Para citar este artículo

Santamaría, L, Alepuz, A. \& Villalonga, R. (2017). QUI... DADA C'EST MOI. Historia de un huevo, por MISE en PLIS. Li-bro/objeto en memoria a Emilio Sdun. Tercio Creciente 13, págs. 109-132. https://dx.doi.org/10.17561/ rtc.mextra1.7 
y el de la multiplicidad al de la reproductibilidad técnica; desde las técnicas, medios y procesos empleados (collage, fotomontaje, tipografías, etc.) a la revisión de las artistas menos conocidas del Dadá y del Surrealismo. Estas estrategias son la evidencia de esa complejidad que alcanza a las artes plásticas, constituyendo los precedentes de la creación contemporánea, con unos recursos más virtuales y aplicados a los medios infográficos y digitales actuales. Gracias a esto, lo que aquí presentamos, nos ha permitido poner énfasis en la vigencia de las vanguardias como fuente inagotable de recursos gráficos y conceptuales, y nos señala el campo abierto en los márgenes difusos que existen entre unas manifestaciones artísticas y otras. the creative strategies of these avant-garde movements, from the concept of the fragmented and the multiplicity of technical reproducibility; from the techniques and proce-sses used media (collage, photomontage, fonts, etc.) to the revision of the lesser-known artists of Dada and Surrealism. These strategies are evidence of that complexity reaches the visual arts, constituting the precedents of contemporary creation, with more virtual and applied to current computer graphics and digital media resources. Thanks to this, what is here has allowed us to emphasize the effect of the vanguards as an inexhaustible source of graphics and conceptual resources, and points the open field in the diffuse margins between some artistic and other events.

Palabras clave / Keywords

Edición, Arte Contemporáneo, Coworking, Libro de Artista, Dadá, Tipografía, Objets trouvés, Ready-mades.

Edition, Contemporary Art, Coworking, Book Art, Dada, Typography, Objets trouvés, Readymades.

Para citar este artículo

Santamaría, L, Alepuz, A. \& Villalonga, R. (2017). QUI... DADA C'EST MOI. Historia de un huevo, por MISE en PLIS. Li-bro/objeto en memoria a Emilio Sdun. Tercio Creciente 13, págs. 109-132. https://dx.doi.org/10.17561/ rtc.mextra1.7 
www.terciocreciente.com
Investigación

\section{Introducción y estado de la cuestión}

Tres artistas de distintas disciplinas teóricoprácticas artísticas: Amparo Alepuz, Rocío Villalonga y Lourdes Santamaría, nos unimos con el propósito de trabajar en colaboración. Así nace el grupo MISE en PLIS, un denominador común desde el que investigar a través de la producción de obra artística con una perspectiva interdiscipli-nar y con el objetivo de abarcar proyectos encaminados a enriquecer nuestra proyec-ción investigadora. Por lo tanto, decidimos trabajar en la edición de propuestas contem-poráneas: desde el libro de artista hasta el álbum gráfico, abarcando no solo su creación sino también la optimización entorno a las estrategias de edición, difusión y comerciali-zación de las obras resultantes.

Nuestro primer trabajo conjunto, OUI... DADA C'EST MOI. Historia de un huevo es un libro-objeto que proyectamos con motivo de la Convocatoria Internacional de libros de Artista, Memorial Emilio Sdun, cuya temática propuesta giraba en torno al estilo Dadá y que fue seleccionado en dicha convocatoria. El nombre del grupo, MISE en PLIS, hace referencia también al estilo Dadaísta, el hilo conductor e inspiración de este proyecto.

En este artículo desarrollamos, a modo de memorándum práctico, la investigación realizada, documentando los procesos iniciales en los que ideamos la propuesta y su contenido y cómo decidimos la forma que íbamos a darle a nuestro Libro de Artista, la metodología del proceso de creación de la obra: el desarrollo de su ejecución, las estrategias de trabajo, edición y posproducción, hasta obtener las conclusiones e incidir en los apoyos y agradecimientos que han hecho posible este libro/objeto de artista.

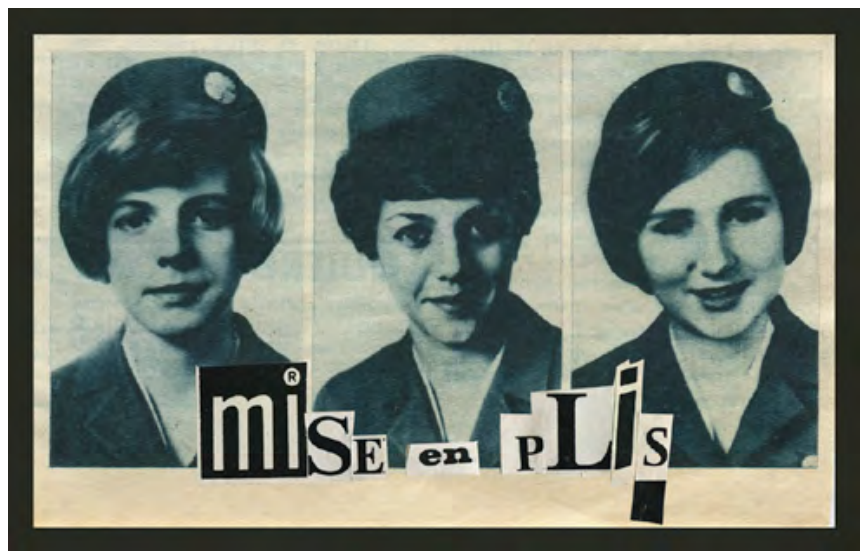




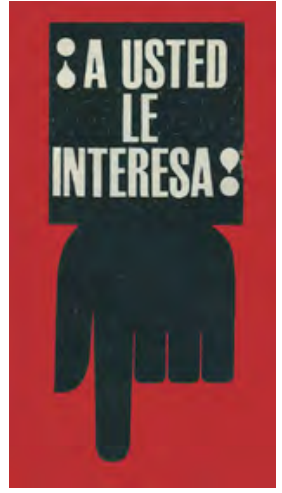

\section{Objetivos y justificación}

El objetivo general de nuestro Proyecto era realizar un libro de artista en el que aportásemos conjuntamente las inquietudes artísticas de cada una de nosotras, los conocimiento que tenemos de las distintas disciplinas en las que estamos especializadas: la ilustración, la edición contemporánea, la escultura y la teoría del arte y que consiguiésemos una obra que se ajustase a la propuesta de la convocatoria a la que íbamos a optar.

Dado que la temática propuesta giraba en torno a Dadá, nuestra estrategia inicial fue realizar un brainstorming y anotar aquellas ideas que fueran surgiendo. Así decidimos resaltar la contemporaneidad del dadaísmo y sus múltiples aportaciones a las técnicas tipográficas, estudiándolas y adaptándolas a los nuevos medios digitales, pero intentando conservar el espíritu de irreverencia y diversión dadaísta. Nuestro Libro de Artista combina una serie de 30 ilustraciones digitales, que rinden homenaje a las tipografías y artistas dadaístas, con una serie de 30 objetos relacionados con los conceptos representados en las láminas. Se pretende lograr la metamorfosis del objeto/libro/artístico; convertirlo en el territorio donde confluyen escritura y arte, con una vida propia, que no repite o imita al mundo exterior, sino que lo recrea de un modo independiente.

Nuestro Proyecto pretende ser un homenaje a los artistas de vanguardia surgidos en el Cabaret Voltaire de Zurich, fundado por Hugo Ball, en 1916, los dadaístas en primer lugar, pero también a los surrealistas, como directos herederos de Dadá. Tristan Tzara es uno de nuestros referentes principales, por transitar de un movimiento a otro, dejando su huella creativa multidisciplinar en todas sus vertientes: poéticas, gráficas, artísticas y literarias.

Dadá es un estilo artístico plenamente vigente, transgresor e innovador, basado en el automatismo, el cadáver exquisito, el objet trouvé, el collage, el fotomontaje, el readymade, y en valorizar el uso de los mass-media y el Manifiesto como medios de difusión y expresión político-artística. El Proyecto trata de reivindicar la contemporaneidad de los dadaístas y sus innovaciones tipográficas, ya que estos hallazgos dadaístas en materia de destrucción del arte, del pensamiento lógico y de la realidad para construir y expresar nuevas creaciones culturales son el fundamento del arte moderno y del contemporáneo, y son la inspiración de nuestro proyecto: la deconstrucción de la tipografía, los juegos de palabras contradictorios (oxímoron) y la revalorización del objeto encontrado, son las claves Dadá que construyen el corpus conceptual y gráfico de nuestro libro-objetoartístico.

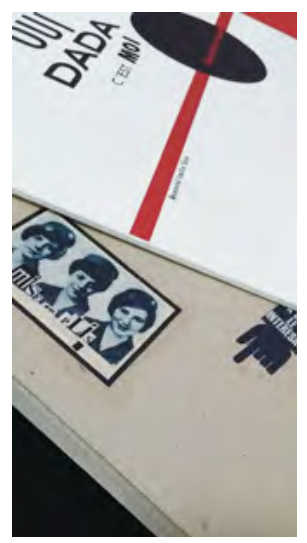




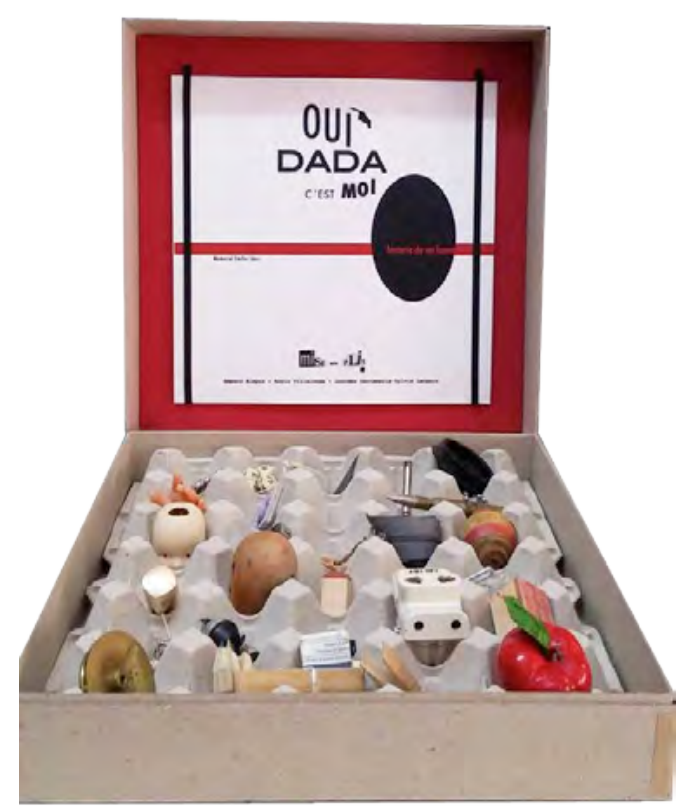

Sintetizamos los objetivos principales:

-Eliminar la separación tradicional de los roles entre pintor y escultor, grabador, tipógrafo o fotógrafo, para crear un nuevo artista multidisciplinar que conozca y domine todas las facetas del proceso artístico, de tal manera que el Libro de Artista sea la fusión de todas esas disciplinas.

-Dotar al objeto encontrado (tridimensional) de signos, significados y significantes para su translación al plano gráfico bidimensional.

-Analizar los aspectos conceptuales de los objetos y representarlos gráficamente, convertidos ya en tropos literarios y visuales simbólicos, metafóricos, icónicos, metonímicos, etc.
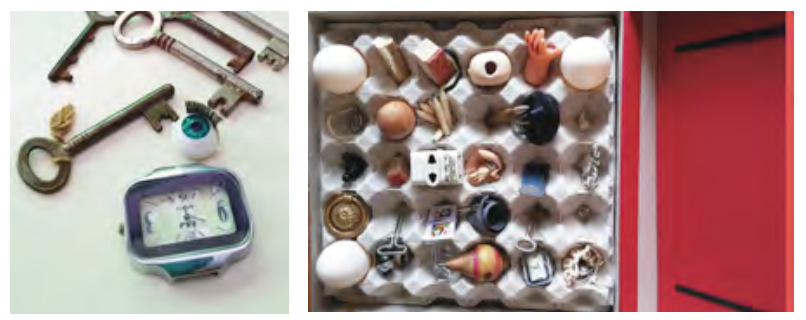

-Investigar en los procesos de creación artística, experimentando con las posibilidades expresivas, plásticas y técnicas de las tipografías y fotograbados, mediante las nuevas tecnologías de fotomontaje digitales y la ilustración digital.

-Experimentar con las tecnologías de la edición de libros para crear físicamente un soporte original y adecuado que materialice el Libro de Artista.

-Reivindicar las aportaciones de los dadaístas, tanto gráficas como conceptuales y su vigencia en el arte contemporáneo. 


\section{Metodología}

La Metodología seguida ha sido, por un lado la Comparativa, para buscar similitudes y relaciones conceptuales, formales y técnicas entre los estilos y artistas dadaístas y surrealistas. Por otro lado, hemos utilizado también la Metodología Analítica, para observar, desmembrar y examinar cada parte de los procesos creativos de los estilos analizados en cuestión, para observar sus causas y efectos y su continuidad en el arte contemporáneo. Han sido básicos para este estudio los libros de Mario de Michelli, Las vanguardias artísticas del siglo XX, y el de Nikos Stangos, Conceptos de arte moderno (2003).

Una vez consideradas las metodologías mencionadas en el estudio previo histórico y teórico, el método de creación práctico utilizado por las integrantes del grupo para materializar nuestro Libro de Artista, ha sido la "metodología del cadáver exquisito": un método sui generis, de carácter experimental y lúdico, seguido por los dadaístas y surrealistas que consiste en emplear las técnicas de fragmentación, alteración y recomposición de la realidad, unidas a las asociaciones inconscientes causadas por los objetos durante su proceso de metamorfosis.

Hemos observado como los manifiestos dadaístas, iniciados y detallados por Tristán Tzara en 1918, promulgan la deconstrucción del lenguaje, de la literatura, del arte y de la lógica, (Tzara, 1963) [1], mediante la deconstrucción de las palabras y su reconstrucción aleatoria, azarosa, como un cadáver exquisito surrealista. Frente a la imagen del mundo que translucía la perspectiva académica, el collage y el assemblage dadaísta y surrealista se expresaban como lo discontinuo, lo interrumpido, los discursos fragmentados, como si fueran la radiografía especular del mundo moderno. En esta tendencia a abarcar el objeto, la imagen y la ruptura semántica, se podrían ilustrar nuevos modos de hacer arte, sin tener que partir necesariamente de categorizaciones tradicionales.

La ambición objetual / espacial desarrollada en este trabajo artístico, no deja de ser el germen de aquello ya experimentado que revolucionó el arte en el siglo pasado: los lenguajes tridimensionales y objetuales ya estaban germinando con el collage. Igualmente, la reproductibilidad sin ninguna finalidad intelectual se ha empleado a menudo como recurso, e igualmente la destrucción del aura de la obra debido a su reproductibilidad técnica, como nos indica Benjamin, (2003) [2] en su texto original, La obra de arte en la época de su reproductibilidad técnica, escrito en 1936 y coetáneo de las vanguardias. Pero está claro que el movimiento Dadá, a pesar de elaborar unas obras con un aparente sinsentido como recurso, estaban cargadas de un intenso mensaje de ruptura de la puesta en escena, al igual que se puede intervenir de distintas formas en el objeto y en el espacio.

\section{Descripción y medios}

Nuestro Libro/Objeto de Artista está planteado no sólo como una labor de equipo que une varias técnicas de creación plástica, sino como una experimentación más plena, real y efectiva en el campo de la edición de libros de artista. Cada una de las artistas que componen MISE en PLIS es especialista en diferentes disciplinas que se han puesto en juego en este Proyecto: Amparo Alepuz es profesora de Ilustración y Publicación y Edición de Proyectos Artísticos; 


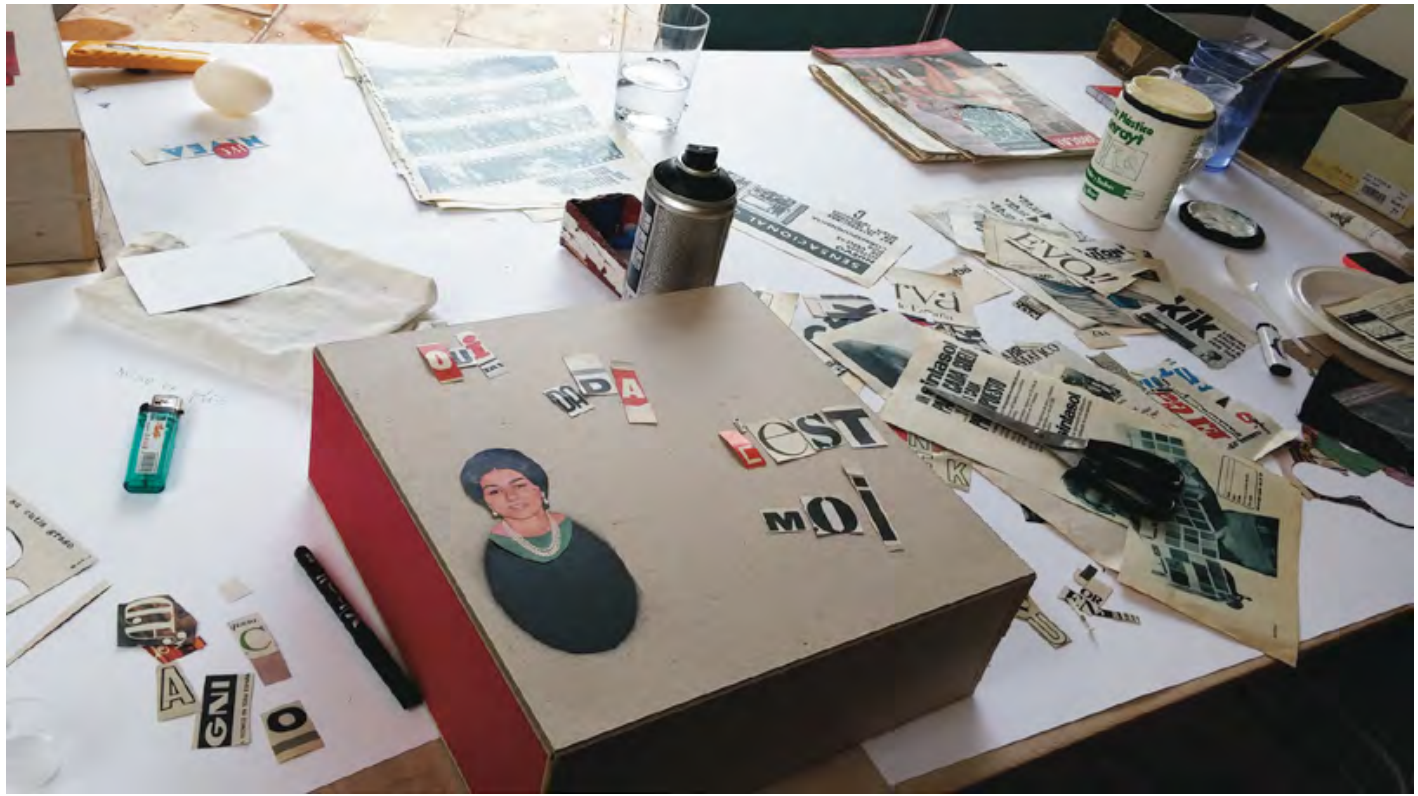

Rocío Villalonga es profesora de Escultura y Proyectos ficcionales; y Lourdes Santamaría es profesora de Teoría de los Lenguajes. Las tres especialidades se aplican para resaltar la TIPOGRAFÍA + OBJETOS + ESPACIO: uniendo ideas, conceptos y enlazando imágenes, para crear obras de arte a partir de objetos preexistentes (ready-made, objet trouvé).

En un principio habíamos barajado diversas propuestas, pero finalmente decidimos diseñar una caja que en su aspecto trasmitiese los valores estéticos dadaístas que motivaban nuestra creación, por lo que nos pareció idóneo que el continente guardará el mismo aspecto que el contenido, así que decidimos que la caja tenía que ser de cartón, como la huevera. Rocío Villalonga la diseñó y se encargó de su construcción. La caja debía tener el volumen suficiente para albergar los objetos contenidos en la huevera y las 30 ilustraciones que decidimos disponer en otra caja con tapa, también de cartón gris. Una goma negra soportaría el libro que acompañaría el trabajo. El color rojo del interior conseguía resolverla impecablemente. El collage hecho a mano en cada una de las cajas, en su parte exterior, superior tapa y laterales, aportaría a la edición la característica de ser cada caja una pieza única y diferente.

El libro objeto que hemos creado consta de una caja (30 x 30 x $10 \mathrm{~cm})$ de cartón reciclado gris, que contiene una huevera en la que se disponen 30 objetos encontrados. Esta caja contiene una segunda caja $(29 \times 29 \times 2.5 \mathrm{~cm})$ con 30 ilustraciones digitales ( $28 \times 28 \mathrm{~cm})$, un libro/catálogo y unos guantes blancos para manipular el contenido.

El compromiso con la convocatoria requería que el libro se pudiera reproducir hasta cinco 


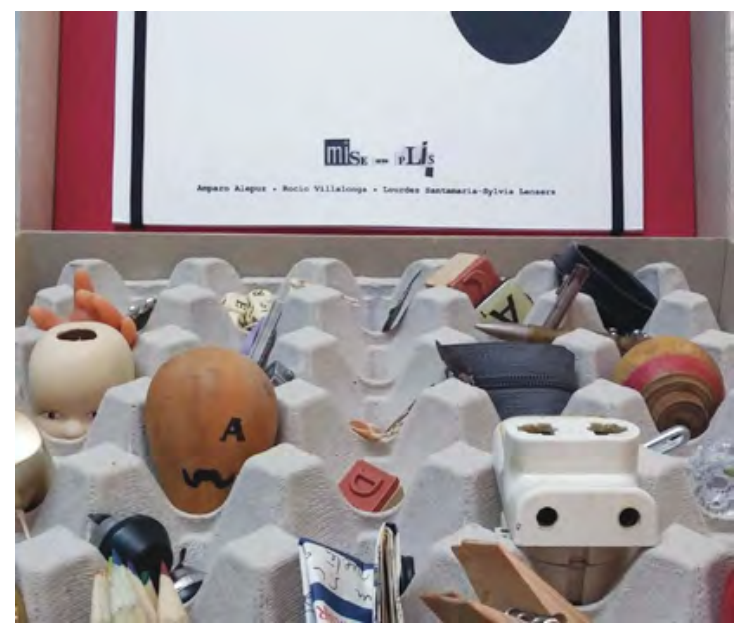

ejemplares, por lo que decidimos realizar simultáneamente la edición completa, dado que el proyecto fue concebido para ejecutarse en sesiones de colaboración entre las tres artistas y a partir de las premisas dadaístas en las que el azar, el juego y el encuentro de soluciones requería de la simultaneidad en la ejecución de cada una de las piezas en lo que se refiere al contenido: objetos, ilustraciones y libro mantienen su similitud, difieren en cada unidad respecto al proceso manual del diseño de la portada, para la que se ha utilizado el collage realizado con recortes de revistas originales de los años '60, en una cita directa al procedimiento de los artistas referentes.

Partimos del significado del título del Proyecto: OUI... DADA C'EST MOI. Historia de un huevo. Oui... Es una palabra oval, ovoide, es como un contenedor semejante al huevo. Se puede jugar con O, la u y la i, todas dentro del kinder sorpresa. DADA C'EST MOI: Hace referencia al estilo que se sigue, en el que se inspira el proyecto, juega también con

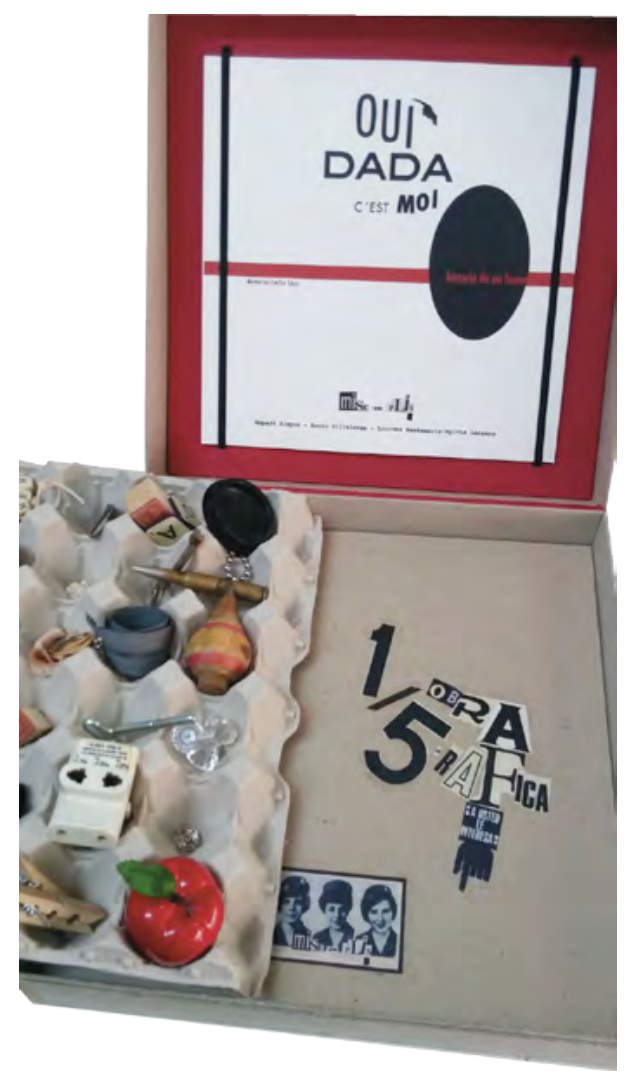

el reverso de Ceci n' est pas une pipe, de Magritte, y en todos los juegos de palabras dadaístas y surrealistas. Historia de un huevo es un homenaje al libro clave de George Bataille, Historia del Ojo, en el que asocia el ojo con el huevo, el testículo, lo frágil y lo resistente (Bataille, 1984) [3].

La idea inicial que gestó la propuesta fue la huevera; llegamos a ella desde el espíritu dadaísta al que nos invitó la convocatoria del Memorial a Emilio Sdun, por lo que empezamos por conseguirlas acudiendo a las 


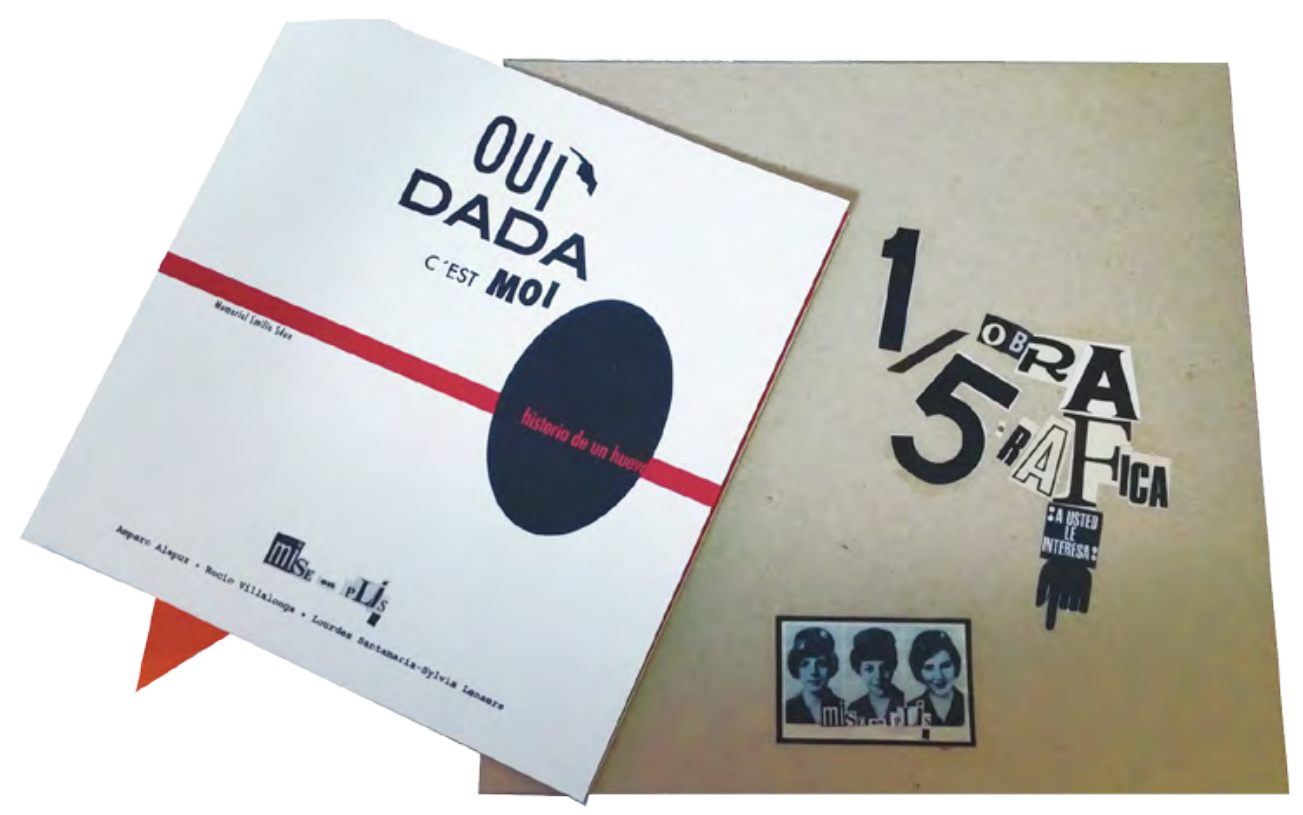

empresas que las producen. Las hueveras iban a ser el soporte de los objetos sobre los que queríamos trabajar, a cada objeto decidimos que le dedicaríamos una ilustración. De ahí surgió la búsqueda de un contenedor de la obra.

Simultáneamente, nos repartimos los treinta espacios de las hueveras, para que cada una de nosotras trabajase sobre diez objetos. Estos fueron proponiéndose a partir de juegos de palabras desde la evocación constante a Dadá. "Bala” fue la primera, de ahí pasamos a componer palabras derivadas como "balada". Pronto surgieron otras que, en principio, se referían al contexto dadaísta: un dado, un monóculo... posteriormente, nuestra búsqueda fue derivando hacia territorios propios, contemporáneos, pero mantuvimos, conscientemente, el mecanismo dadaísta de creación que nos sedujo desde el principio: el azar, el juego, el objeto encontrado. El Libro de Artista es pues, un contenedor tanto de objetos como de ilustraciones.

TIPOGRAFÍAS: Una de nuestras palabras claves y punto de partida son las tipografías dadaístas, pero también las combinamos con otras maneras de retruécanos y recursos lingüísticos: Sudokus, crucigramas, emojis (emoticonos considerados como los jeroglíficos digitales del siglo XXI), oxímoron, y toda clase de figuras alegóricas, simbólicas, metafóricas, etc. 


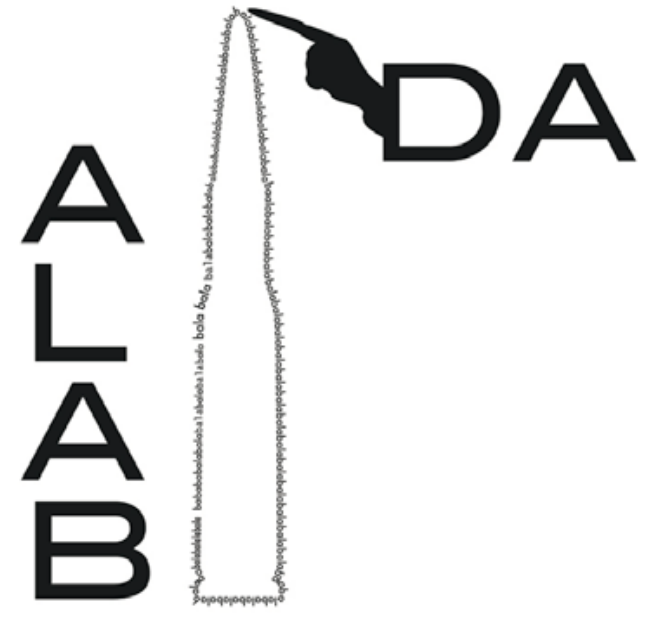

Amparo Alepuz. BALADA. 2016. Ilustración digital.

Las tipografías que utilizamos para este Proyecto son digitales, aunque empleamos tipos de imprenta y recortes de tipografías de revistas de la década de los 50’ y 60' para tratarlos como elementos gráficos y objetuales. Las fuentes empleadas son la Futura, Century Gothic, Bauhaus, Arial, Blair Medium, etc. Las tipografías han sido tratadas como un elemento plástico en un diseño de gráfica expandida, bien desde las opciones que nos ofrece la manipulación de su formato manteniendo su condición, o bien, han sido contorneados para convertir los textos en dibujos vectoriales pudiéndolos así transformar libremente, como si se tratase de objetos. La manipulación digital a la que hemos sometido las tipografías para construir nuestras ilustraciones remite al juego, a las decisiones azarosas y a la poesía visual. Empleamos el software Adobe Illustrator

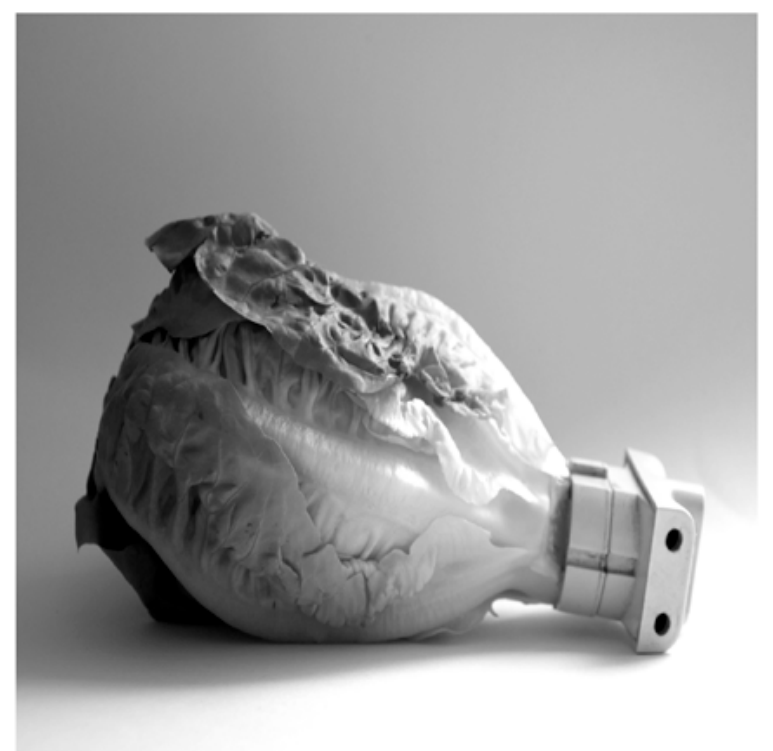

Rocio Villalonga. Enchufe. 2016. Fotografía. para trabajar imágenes vectoriales y Adobe Photoshop para el tratamiento de imágenes de mapa de bits.

Otra fuente de inspiración han sido los MATERIALES/OBJETOS, encontrados al azar y/o elegidos deliberadamente en función tanto de su poder de evocación de ideas y conceptos, como de su materialidad, sus propiedades físicas y táctiles, texturas: tela, madera, yeso, hierro, piedra, alambre, etc. Los 30 objetos se disponen en una huevera como contenedor de poemas visuales, a manera de los dadaístas, pero también de Joan Brossa y Chema Madoz. Los poemas visuales ponen en valor a los objetos, estableciendo un dialogo entre los mismos. 


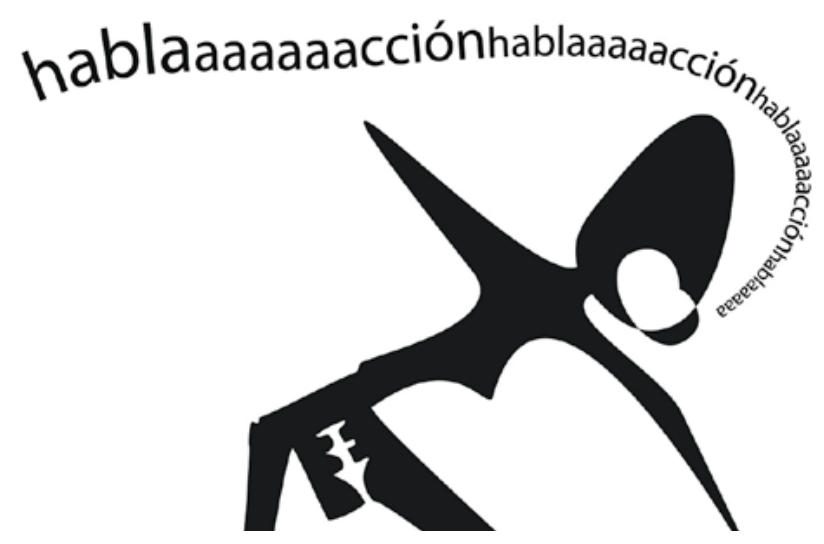

Amparo Alepuz. Hablaacción. 2016. Ilustración digital. Detalle.

Así, para representar objetualmente a Tristan Tzara se escogerá un monóculo, que se encuentra fortuitamente con unas pestañas postizas de cabaretera berlinesa, iluminadas por una pila voltaica sobre una caja de huevos de porcelana. Otro objeto encontrado, una bala, se convierte en un poema visual en su traslación a la lámina, dibujada y perfilada con la misma palabra, y se retuerce y estira creando una grafía, BALADA, que homenajea al dadaísta Hugo Ball y al futurista Giacomo Balla. Unas CUCHILLAS reales, inesperadamente aparecidas sobre una mesa, se transforman en la estremecedora palabra ABLACIÓN, como una denuncia de unas prácticas brutales, por desgracia aún existentes.
Poco a poco los objetos fueron mutando conforme íbamos avanzando en la propuesta. Día a día fuimos acumulando objetos, algunos encontrados entre los muchos cachivaches que guardamos en nuestros estudios, otros los compramos en tiendas de objetos curiosos e inútilmente atractivos y otros fueron arrancados de su funcionalidad para formar parte de nuestro libro. Uno a uno los íbamos situando en los huecos de las hueveras. Simultáneamente fuimos realizando las ilustraciones, cada una de nosotras realizó diez, una por objeto, mediante estrategias y técnicas diferentes en cada una de las artistas, pero manteniendo la temática, estilo y espíritu dadaísta como hilo conductor. 


\section{Análisis y resultados}

\section{Tipografías vectoriales $=$ Dadá + hípster + emojis:}

La Ilustraciones realizadas por Amparo Alepuz son digitales, se ha empleado el software Adobe Illustrator. Todas ellas contienen dibujos vectoriales combinados con tipografías que, en la mayoría de los casos, han sido trazadas para convertirlas en dibujos y poderlas manipular. La intención era seguir una línea en la que se consiguieran composiciones visuales a modo de poemas gráficos en las que se trasladase a la gráfica contemporánea el espíritu del movimiento Dadaísta y su legado, empleando el mínimo número de elementos y una paleta restringida como cita directa a la estética Dadá.

Para crear las ilustraciones se ha partido de una postura intuitiva, de juego, de búsqueda y encuentro casual, desde la aproximación sensible y el análisis de los objetos elegidos. Esta aproximación dadaísta ha dado pie a crear una serie de elementos gráfi-cos a partir de cada objeto y su denominación sustantiva, la palabra que los identifica o nombra en nuestra legua u otra (objeto y su palabra; palabra y sus connotaciones; pala-bra y sus derivaciones; juego de palabras; poética visual).

La tipografía se ha utilizado como herramienta de creación, tanto si se la respeta en su formalismo como si se trasgreden sus normas, rompiendo las escalas, estirando sus nodos o deformando su estructura, se convierten las letras y las palabras en figuras o paisajes construidos. La imagen que resulta de la propia palabra y su escritura, de-pendiendo de la fuente, el tamaño que se le aplique, el grosor o los contornos, los obje-tos y su representación, aluden por analogía, por cita o por persistencia a una serie de conceptos que, en la compleja cultura visual contemporánea, funcionan como un cons-tructo, como una imagen llena de significado.

Los referentes formales han sido encontrados en Dadá y otros movimientos coetáneos de vanguardias artísticas (De Michelli, 2006) [4] como el Surrealismo y sus estrategias de creación: la casualidad, la experimentación, l’object trouvé, el ready ma-de. También en el Futurismo y en la Bauhaus a través de composiciones formalistas (Stangos, 2004) [5] que trasgreden los cánones clásicos: reticulares, fondos sin límite, espacios en blanco. Estas estrategias nos trasladan a la contemporaneidad, como vemos en el arte conceptual, el net art, el concept art, la poesía visual, el diseño gráfico, la pu-blicidad, y a través de elementos análogos como son los iconos, símbolos, emoticonos...

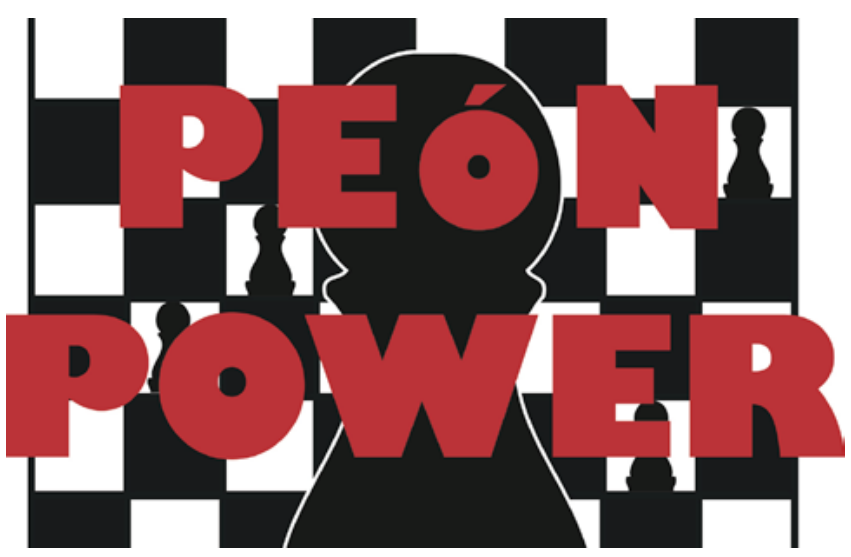

Amparo Alepuz. PEÓN POWER. 2016. Ilustración digital. Detalle. 
www.terciocreciente.com
Investigación
Dibujar una llave con la pluma de trazados vectoriales, a partir de la imagen fo-tográfica de una llave antigua encontrada casualmente en internet, manejar azarosamente sus nodos hasta dibujar una bailarina con cabeza en forma de corazón que entre sus piernas esconde lo que puede ser una cuchilla, mientras entona hablaaaaacciónhablacciónnnn sobre una alfombra roja, puede acabar simbolizando la versatilidad entre la fuerza y la sensibilidad que reviste el carácter femenino contemporáneo, o simplemente ser una imagen producto del juego de la creación que se ha cerrado cuando se ha consi-derado que estaba resuelta, un ejercicio de pura creación en el que la ablación, Mutila-ción Genital Femenina, está en el inconsciente.

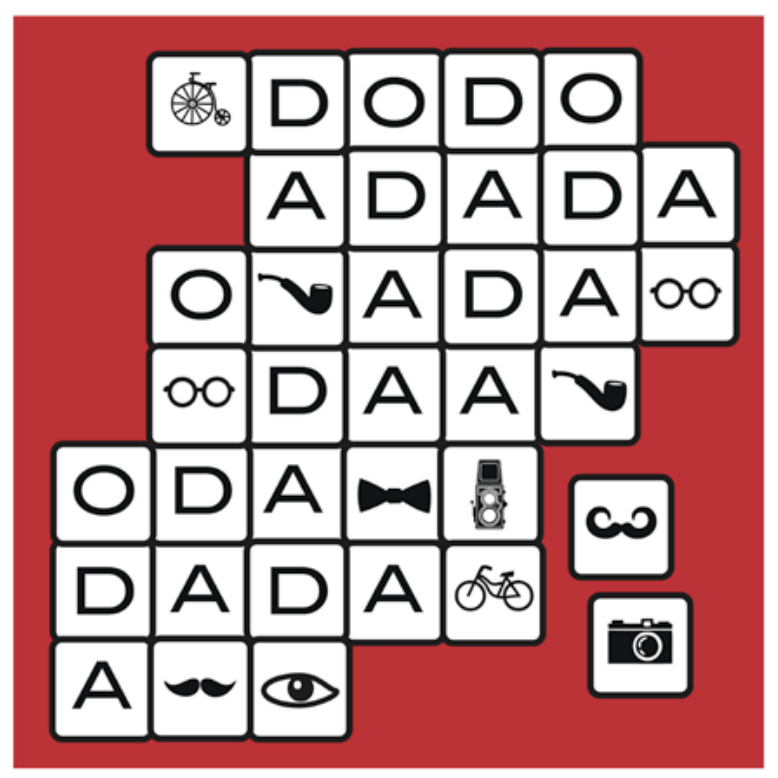

Amparo Alepuz. ODAADADA. 2016. Ilustración digital.
Componer un scrabble, desde el dibujo de sus fichas, cuadradas y de apariencia lustrosa, nos remite directamente al uso de efectos de contorno que hacen que el cua-drado adquiera profundidad y volumen; así, en un solo gesto con el ordenador se consi-gue el efecto que antes debía sombrearse a lápiz... Sobre ellos las letras que componen DADÁ+ al azar una $O$, y un sinfín de posibles combinatorias: ADO; DODO; DADA; ADO-RODADA, todas ellas sin rigor y compuestas con un fin meramente estético. Una cita a DADÁ, rojo de fondo que contemporáneamente da un efecto velvet, de alfombra roja. Y como letras, una serie de símbolos para los que se recurre a una tipografía Hipster en-contrada en dafont.com, y que se ofrece $100 \%$ gratuita. Tras indagar todo el alfabeto se seleccionaron aquellos iconos que evocaban a DADÁ, en un ejercicio de apropiacionismo como el que realizaban los dadaístas, al recortar los periódicos para componer sus poemas y sus carteles.

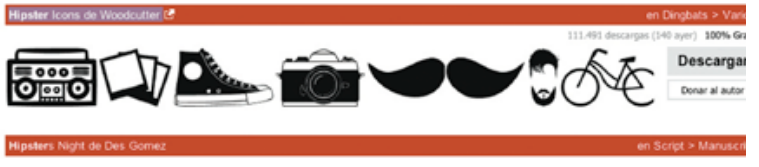

Evidentemente, no se trata de apropiarse de esta tipografía, sino que se con-vierten los iconos seleccionados, con la herramienta de crear contornos, en dibujos que se pueden manipular. Así se transforman, como por ejemplo ocurre con el icono de las gafas, para conseguir que las gafas hipster de pasta negra se ajusten a la estética DADÁ, dibujando unas lentes circulares al estilo de la época citada. Y se crean iconos nuevos, como el ojo, en una cita al libro clave de George Bataille, Historia del Ojo (1928). El resul-tado pretende evocar el espíritu DADÁ a través del contexto contemporáneo de las tri-bus urbanas y sus símbolos, los juegos de palabras y la poética visual. 


\section{Reproductibilidad del objet trouvé:}

La reproductibilidad técnica que aporta el collage a través de su digitalización, es un elemento que investiga Rocío Villalonga con la obra que presenta en este libo de autor. En ella se evidencia el fragmento, su autonomía, y a su vez su dependencia res-pecto a una unidad mayor. La digitalización de un proceso analógico como es el que se emplea tras hacer los collages, posibilita que estas obras se puedan extender infinita-mente si así se decide. Por lo tanto, es oportuna la reflexión de Walter Benjamín al res-pecto:

\section{Hacia mil novecientos la reproducción técnica había alcanzado un estándar tal, que le permitía no sólo convertir en objetos suyos a la totalidad de las obras de arte hereda-das y someter su acción a las más profundas transformaciones, sino conquistar para sí misma un lugar propio entre los procedimientos artísticos. Nada es más sugerente pa-ra el estudio de este estándar que el modo en que sus dos manifestaciones distintas_la reproducción de la obra de arte y el arte cinematográfico_retroactúan sobre el arte en su figura heredada. (Benjamin, 2003, ps.40-41) [6]}

Las obra gráfica que aquí presentamos, son en sí mismos documentos de unos procesos de multiplicación y fragmentación. En ocasiones, nos vimos atrapadas en un constante intento de un efecto serializador, que corresponde a una estrategia de presentación de elementos en un espacio. Las teorías de Morin y Lyotard en relación a la auto-rreferencialidad, (Cifre, 2003) [7] y Goodman en relación a la fragmentariedad, como dos de las prácticas discursivas más características de los discursos del arte contempo-ráneo, han supuesto un profundo apoyo para fragmentar el objeto y su carga semántica hasta subvertirlo.

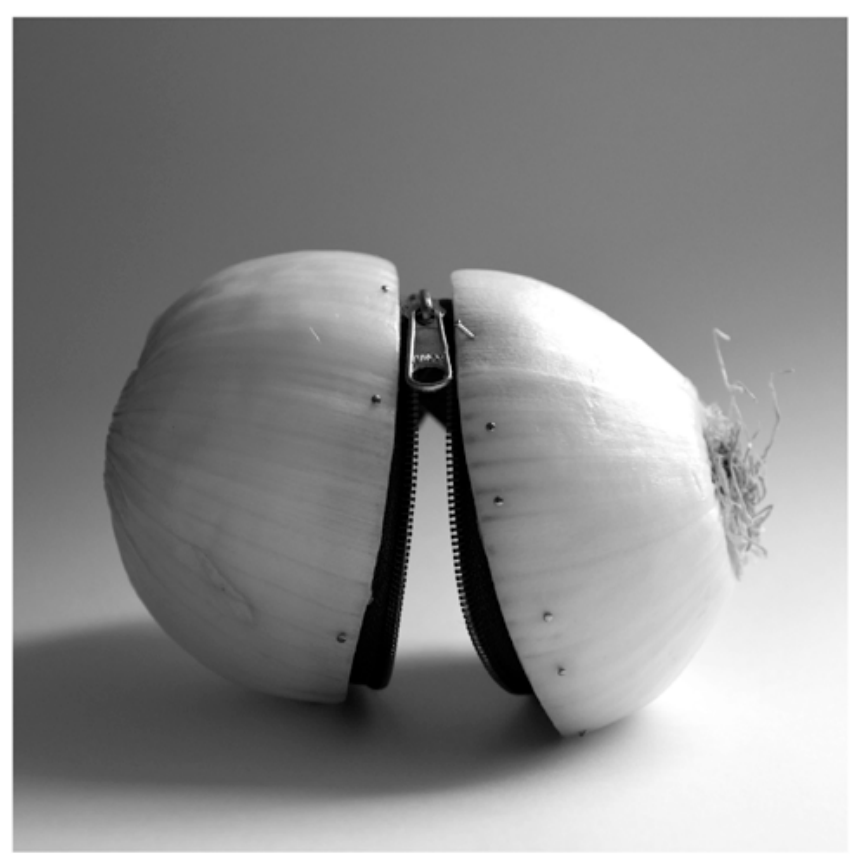

Rocio Villalonga. Cremallera. 2016. Fotografía.

Podríamos decir que en su inicio, nos enfrentábamos al objeto desde un punto de vista aristotélico, en el que las cosas están constituidas por su forma sustancial y la materia que las conforman, aquello por lo cual una cosa es como es y aquello de lo que están hechas. Sin embargo, este modo de analizar los objetos con los cuales nos propu-simos trabajar, se tornaba demasiado evidente en nuestra pretensión de desarrollar un discurso dadaísta fragmentado. Es por ello que consideramos que la idea platónica en relación a su concepto acerca de las cosas era más apropiado, ya que éste pretendía se-parar nuestra realidad cotidiana, del mundo de las ideas, por lo que ello nos permitía un discurso más abstracto. 
El empleo de la fotografía en nuestra experiencia artística bidimensional, y la objetual en la tridimensional con la adición de distintos módulos, no dejan de ser herramientas con las cuales nos familiarizamos en nuestros inicios y fueron diversificán-dose y a su vez concretándose, en obras en las que lo gráfico y lo tridimensional dialo-gan. Desde siempre la idea de fragmento forma parte de nuestro modo de trabajar. Las estrategias de la multiplicación y de la fragmentación, son la evidencia de esa compleji-dad que alcanza a las artes plásticas, constituyendo los precedentes de la creación con unos recursos más virtuales. Chema Madoz, por ejemplo, es uno de los referentes visua-les más significativos en la construcción de nuevos objetos autorreferenciales (Coleman, 1999) [8].
Fue detonante así mismo en este trabajo, la observación de la relación entre la búsqueda de sentido y la calidad de la obra. El empleo de filtros, como papel vegetal y la superposición de imágenes impresas en acetatos, superpuestas sobre las fotografías impresas en papel, nos permiten el empleo de la fragmentalidad de la imagen con un acercamiento a Dadá en lo relativo a la fragmentación que empleaban en sus textos grá-ficos a través de las mezclas tipográficas. Así la semántica se revierte a través de la pro-pia fragmentación y los símbolos tipográficos. La posibilidad, a través del collage, de in-corporar nuevos elementos que configuren un nuevo imaginario, permite a través de la fragmentación otorgar otros valores semánticos, no explicitados en la nomenclatura del propio objeto.

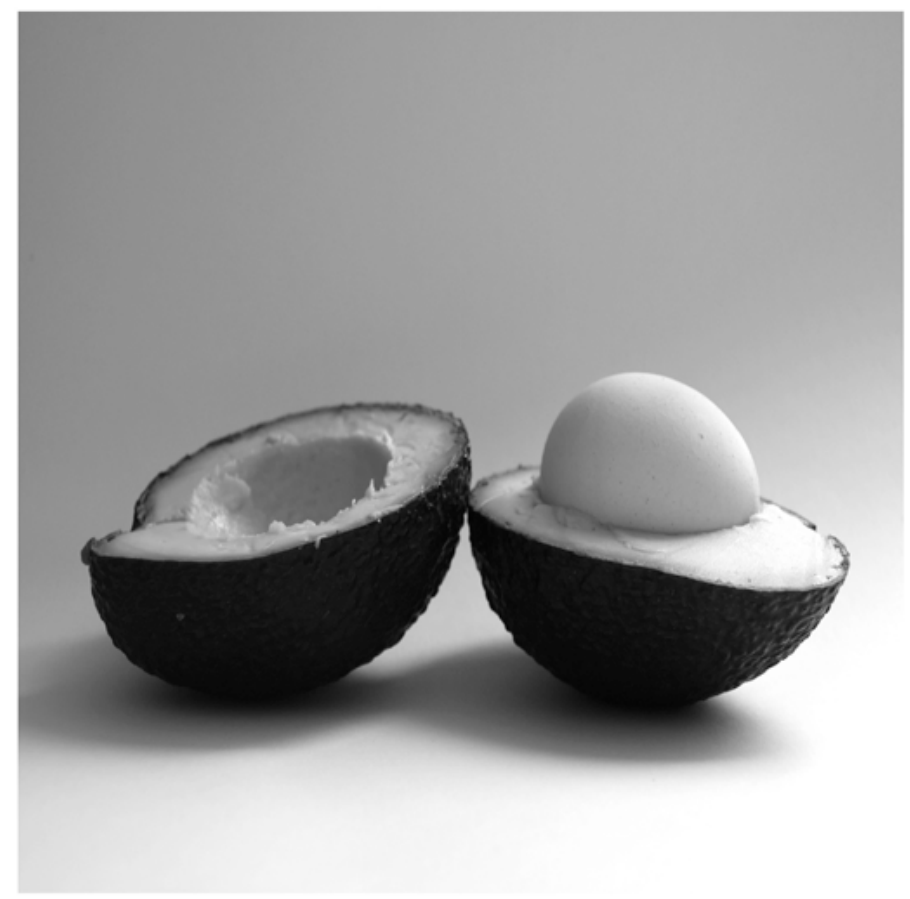

Rocio Villalonga. Huevo. 2016. Fotografía. 
El empleo del objeto tridimensional como punto de partida para comenzar a trabajar, la imagen que representa a ese objeto, y las variaciones surgidas resultado de la fragmentación a las que son sometidos a través del collage, unido al juego de signifi-cados, permite que el discurso se rompa y se una, a través de la observación de lo que en la obra resultante acontece. El juego que permite el objeto de partida para cada collage, da pie a experimentar con sus valores tanto semánticos como sintácticos, en los que la propia fragmentalidad participa para, lúdicamente, generar un discurso coherente. Así, de esta experimentación han surgido innumerables versiones destinadas a cada objeto (el abrelatas, el clek, la cremallera, el enchufe, el huevo, la manzana, el certificado, las pinzas, el tapón, el tirador), desencadenando múltiples diálogos que han ido confor-mando las ilustraciones. Resultado de todo ello, es el desarrollo de unas estrategias de descomposición de la propia imagen y los textos, deconstruidos en ocasiones y en otras rememorando los significantes implícitos al objeto.

\section{\#DadaFemmeFatale”:}

Lou et Syl es el nombre del grupo formado por Lourdes Santamaría Blasco y Sylvia Lenaers Cases. Los collages / fotomontajes digitales realizados para este Li-bro/Objeto de Artista, son un homenaje a las mujeres dadaístas que permanecieron a la sombra de los artistas Dáda más reconocidos. La serie realizada, \#DadaFemmeFatale”, aporta la “otra” visión, complementaria y conjunta, dentro de este trabajo multidiscipli-nar, procesual, técnico y conceptual realizado por las diferentes artistas de MISE en PLIS, especializadas en diferentes temáticas.
Por lo tanto, no se parte de la tipografía ni de los materiales, procesos y proce-dimientos como referencia fundamental, aunque se usen en mayor o menor medida, sino que partimos desde una perspectiva de género y de reivindicación del importante papel que ellas, las femmesdadasurrealistes, jugaron en los años convulsos de la Europa entreguerras, yendo desde el Cabaret Voltaire de Zurich a los bares de las calles de Montparnasse o Montmartre de París (De Diego, 1995) [9]. O desde Dada al Surrealis-mo. O desde la visión masculina a la femenina ¿Diferentes o semejantes?... Al menos va-mos a verlas con cierto detenimiento en estos collages que interpretan sus vidas y sus obras.

Cut with the Kitchen Knife Dada through the Last Weimar: Hanna Hoch, califica-da por el diario The Telegraph en 2014 como una "art's original punk" (Hudson, 2014) [10], era, por derecho propio, una artista pionera del collage, dándole una mirada femi-nista y andrógina al mismo tiempo a sus obras, cuestionando en ellas el estándar de be-lleza femenina, la política belicista alemana o el matrimonio y la sexualidad heteronor-mativa. Por ejemplo, su collage titulado Dompeteusse (Tamer) 1930, mezcla en un cuer-po hermafrodita la fragilidad de un rostro de porcelana y los brazos musculosos de un domador de circo. La reciente exposición Dada Afrika-Dialogo con el otro, muestra obras de Hanna Hoch y de Shopie Taeuber al mismo nivel que las de Grosz, Arp, Haus-mann o Man Ray. Sin embargo, durante su época, la mayor parte de ellas eran sólo las novias, esposas, amigas, musas, "chicas de los recados”... según decía Raul Hausmann de su amante Hanna Hoch, infravalorando y oscureciendo el trabajo artístico que estas rea-lizaron a contracorriente, ya sea desde el diseño, el collage, la fotografía, la performance, etc. 
Investigación

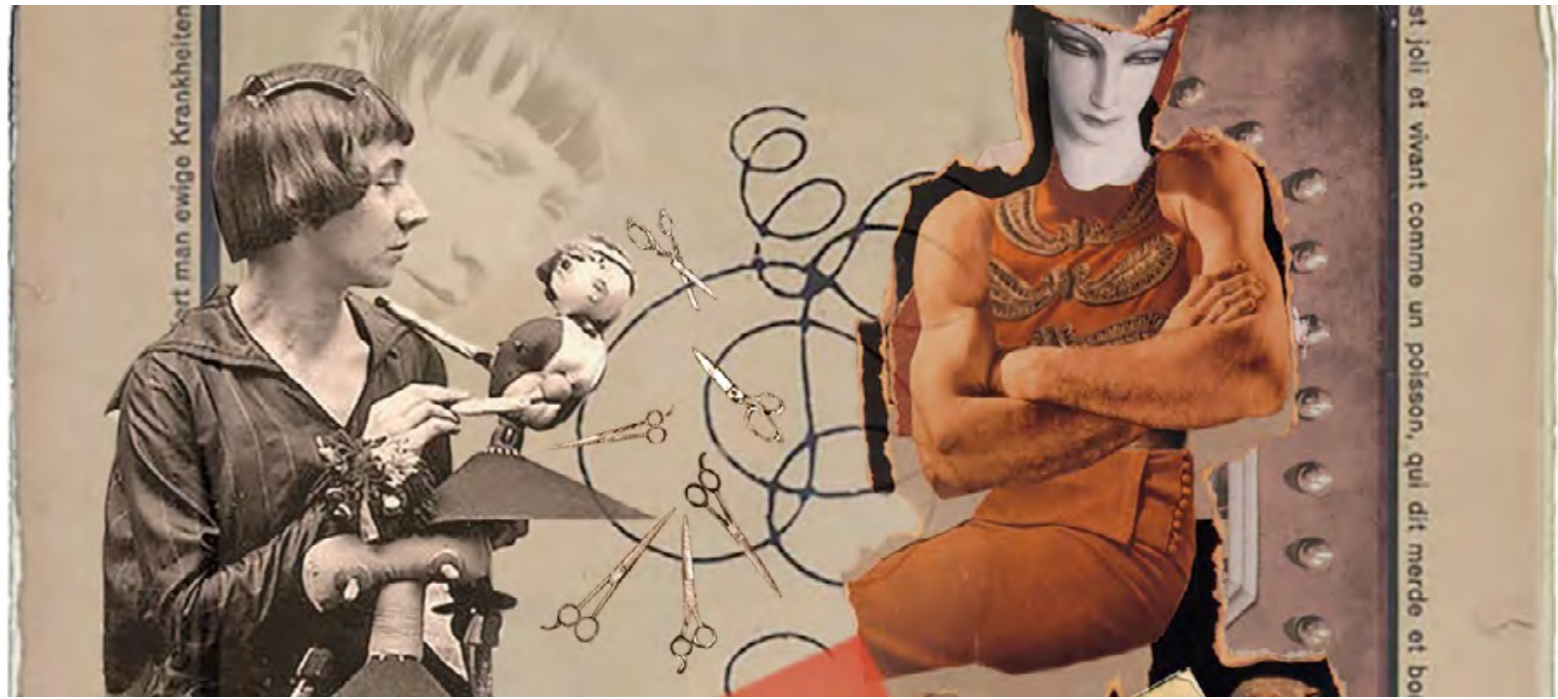

Lou et Syl. Cut with the Kitchen Knife Dada through the Last Weimar. 2016. Collage digital. Detalle.

Construcción Dáda: Shopie Taeuber-Arp realizaba sus diseños inspirándose en la Bauhaus y en el constructivismo, la geometría, el espacio y la línea de los Merz de Kurt Schwitters y de Jean Arp, su marido. Fue pintora, decoradora, marionetista y baila-rina del Cabaret Voltaire, como Emmy Hennings, una de las dadaístas más desconocidas (Greil, 2005) [11] del círculo de Munich y Zurich. Hennings tuvo una vida turbulenta re-pleta de excesos: sexo, drogas, poesía anarquista y matrimonio dadaísta con Hugo Ball que, posteriormente, renegó del dadaísmo y se reconvirtió en un ferviente católico. "Rastros de carmín en el Cabaret Voltaire" es el título del collage que le rinde homenaje.

Los surrealistas, herederos del talento y la misoginia de los dadaístas, conside-raban a la mujer como musa y modelo, sumisa esposa o excitante amante, ensoñación onírica o prostituta complaciente. Pero nunca como una artista a su nivel, si acaso unas diletantes veleidosas que experimentaban con el arte. No obstante las dificultades, mu-chas consiguieron realizar sus obras, más reconocidas en la actualidad que en su época. Estas mujeres representan en sí mismas la esencia de la auténtica modernidad y liber-tad; su papel en las vanguardias es único e insustituible y precursor de temas como el cuestionamiento de la identidad, de la sexualidad y de los géneros.

La acuchilladora de armadillos: Dora Maar buscó su medio de expresión artísti-ca a través de la fotografía, dotándola de atmósferas oníricas y monstruosas, influencia-da por su amigo Georges Bataille. Una de sus fotos más conocidas fue la que realizó al feto de un armadillo y tituló como Pére Ubu, 1936, inspirado en la obra de teatro Ubú Rey de Alfred Jarry. El collage realizado, La acuchilladora de 
armadillos, sintetiza una anécdota, contada por Fernando Castro Flórez, de su relación tormentosa con Picasso: Dora solía jugar con un cuchillo, haciéndolo pasar velozmente entre los huecos de sus dedos enguantados; a veces se hería y sangraba manchándolos. Esa acción y esos guan-tes ensangrentados fascinaban a Picasso, que llegó a pintar unos guantes sobre unas manos femeninas para una fotografía de Man Ray. Estos elementos recurrentes, las ma-nos, los cuchillos y el armadillo, son el homenaje a esta artista más conocida por ser "la mujer que llora”, como la llamaba Picasso, que por sus fotografías.

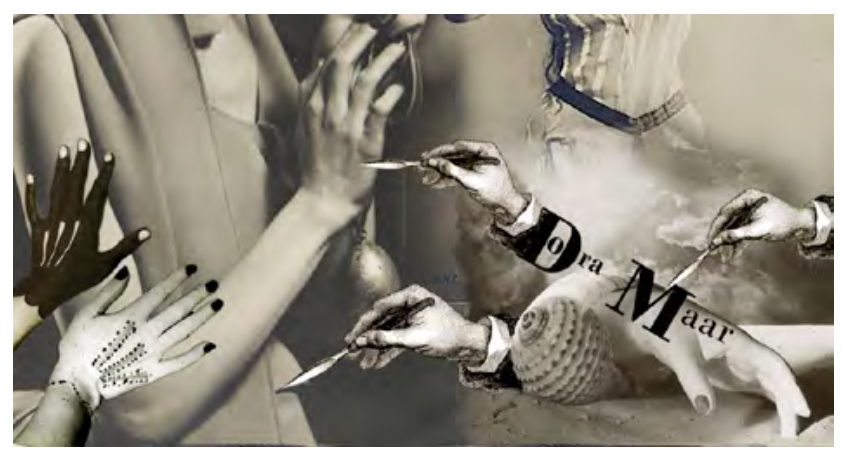

Lou et Syl. La acuchilladora de armadillos. 2016. Collage digital. Detalle.

Deconstruyendo armarios: Claude Cahun (alias de Lucy Schwob), aficionada al teatro, a la poesía y la escritura, utilizó el simulacro para confeccionarse diversas iden-tidades, que construía, deconstruía y reconstruía una y otra vez a través de sus fotogra-fías y collages de ella misma. De esta manera, el artificio se convertía en una realidad más allá de la realidad, doblegando las fronteras de la identidad y el género, como seña-la Juan Vicente Aliaga (2002) [12]. Cahun convertía lo dual en unidad, en interrogación y respuesta invitando a la reflexión y a la flexibilidad; ella no dudó en abrir los armarios para airearlos del olor a prejuicio y convencionalismo de la sociedad. La artista fue una multifacética intelectual, valerosa y muy implicada socialmente, que llevó su libertad y convicciones hasta la condena a muerte por los nazis. Afortunadamente, el final de la guerra la libró de ese peligro.

M opeh!M: Meret Oppenheim fue capaz de convertir en una Venus in furs una simple taza y un plato de loza, recubriéndola de pieles. $\mathrm{O}$ convertir unos zapatos de ta-cón atados como un pollo en un elemento de fetichismo caníbal. Ella conseguía radio-grafiar la cotidianidad, transmutando los objetos cotidianos y anodinos en discursos re-flexivos y complejos, y nos mostró una intimidad impúdica, oculta y ocultada que nos desasosiega y fascina (Ammann, J.C, et altri. 1989) [13]. Oppenheim aparece convertida simplemente como una musa de Man Ray en la historia del arte, cuando en realidad no sólo fue inspiradora, sino que fue, ante todo, artista por méritos propios.

Barbette, la belle amie de Rrose Selavy: Y ¿quién es Barbette? Un ser Féminin-Masculin, monsieur Vander Clyde de día, mademoiselle Barbette de noche, transformis-ta de cabaret, Drag Queen avant la lettre, el ensueño de una feminidad hecha de artificio, ligueros y maquillaje que fascinaba a Jean Cocteau y especialmente a Man Ray, que l@ fotografío en su camerino en desabillé y en el trapecio, realizando lo más difícil toda-vía... Un rostro velado tras la carta del andrógino nos insinúa que Rrose Selavy, alias de Marcel Duchamp, pudo ser su amig@, con la que compartía secretos de tocador, o tal vez unos sombreros emplumados, definitivamente muy demodés incluso en los años 20 y 30. 
Investigación
Souvenirs de Kiki: Kiki de Montparnasse, alias de Alice Prin, era el arquetipo de la garçonne parisiense, una mujer libre y desinhibida, cantante y bailarina de cabaret, modelo de pintores, musa y amante de Man Ray, y actriz en varias películas surrealistas, como L'Étoile de Mer, 1928. También dibujaba y escribió sus memorias en Souvenirs re-trouvés, en 1929, que fueron prorrogadas por Ernst Hemingway y Foujita. Las máscaras africanas y dos de los múltiples rostros totémicos de Kiki, componen este homenaje a un personaje simbólico de una época frenética, cuando París era una fiesta, la vida transcu-rría entre tragos de absenta y bailes apaches, con la locura acechando en cada esquina de París.

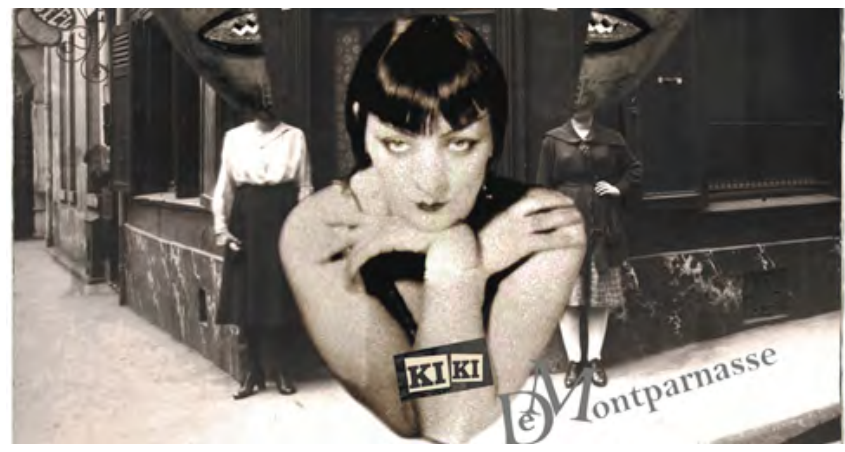

Lou et Syl. Souvenirs de Kiki. 2016. Collage digital. Detalle.

Lee Miller' eyes: Lee Miller era una mujer de belleza fascinante y vida novelesca; varios novios, amantes y maridos de diversas nacionalidades surcan como estelas su vida. Pasó de ser la modelo, musa y colaboradora de Man Ray y actriz con Jean Cocteau, a ser fotoperiodista de guerra y fotografiar campos de exterminio y ciudades arrasadas en Alemania. En el entreacto protagoniza otra foto icónica, lavándose las cenizas y el ho-rror en la bañera privada del führer en Berlín... De entre todas sus fotos escogemos la tomada durante los bombardeos de Londres, con gafas de soldador junto a una amiga enmascarada; ambas ocultan sus ojos. Sin embargo, esos ojos son los que Man Ray re-trata y recorta obsesivamente para crear su Objeto para destruir, 1932, dedicado a Lee Miller, con este texto:

Corte el ojo de una fotografía de alguien que ha sido amado pero que ya no ve más. Pegue el ojo al péndulo de un metrónomo y regule el peso hasta encon-trar el tiempo deseado. Continué así mientras pueda soportarlo. Con un martillo bien preparado, intente destruirlo de un solo golpe. (Andrews, 1994) [14].

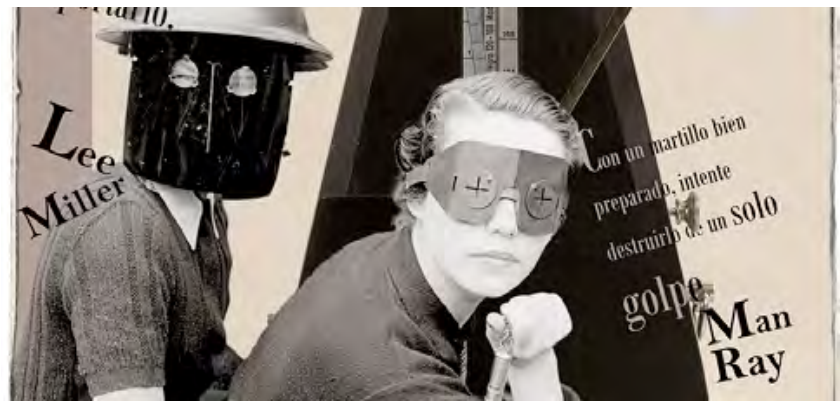

Lou et Syl. Lee Miller eyes. 2016. Collage digital. Detalle.

\section{Discusión y conclusiones}

Desde siempre la idea de fragmento (lo fragmentado) ha formado parte de nuestro modo de trabajar. Las estrategias de la multiplicación y de la fragmentación, son la evidencia de esa complejidad que alcanza a las artes plásticas, constituyendo los pre-cedentes de la creación con unos recursos más virtuales. Gracias a 
esto, lo que aquí he-mos presentado nos ha permitido poner énfasis en el campo abierto, en los márgenes difusos que existen entre unas manifestaciones y otras.

Todo ello ha provocado la incapacidad de encajonar estas obras, este Libro/ Ar-tista / Objetual, en una categorización excesivamente férrea. Decimos incapacidad debi-do al mismo tiempo a la versatilidad y multiplicidad de la obra realizada. Con estos re-sultados se puede poner énfasis en la capacidad que tiene el artista dadaísta (y las artis-tas que seguimos su método de creación) para aglutinar todo tipo de referencias, tecno-logías y medios que provienen de diversos campos del saber.
Durante el proceso de trabajo ha habido un objetivo inicial: hallar los rasgos diferenciadores entre lo interno y lo externo de cada objeto. Ello ha provocado una sub-versión de significantes a medida que avanzaba el trabajo creativo. De este modo se han generado interferencias entre significante, significado y aspectos visuales intrínsecos al propio objeto. Todo ello ha permitido la desmaterialización del objeto en la génesis del discurso gráfico, produciéndose un diálogo de contrarios, que recrea el mundo de lo lú-dico y de la trasgresión de conceptos. La realidad física de lo representado se ha puesto pues bajo cuestionamiento.

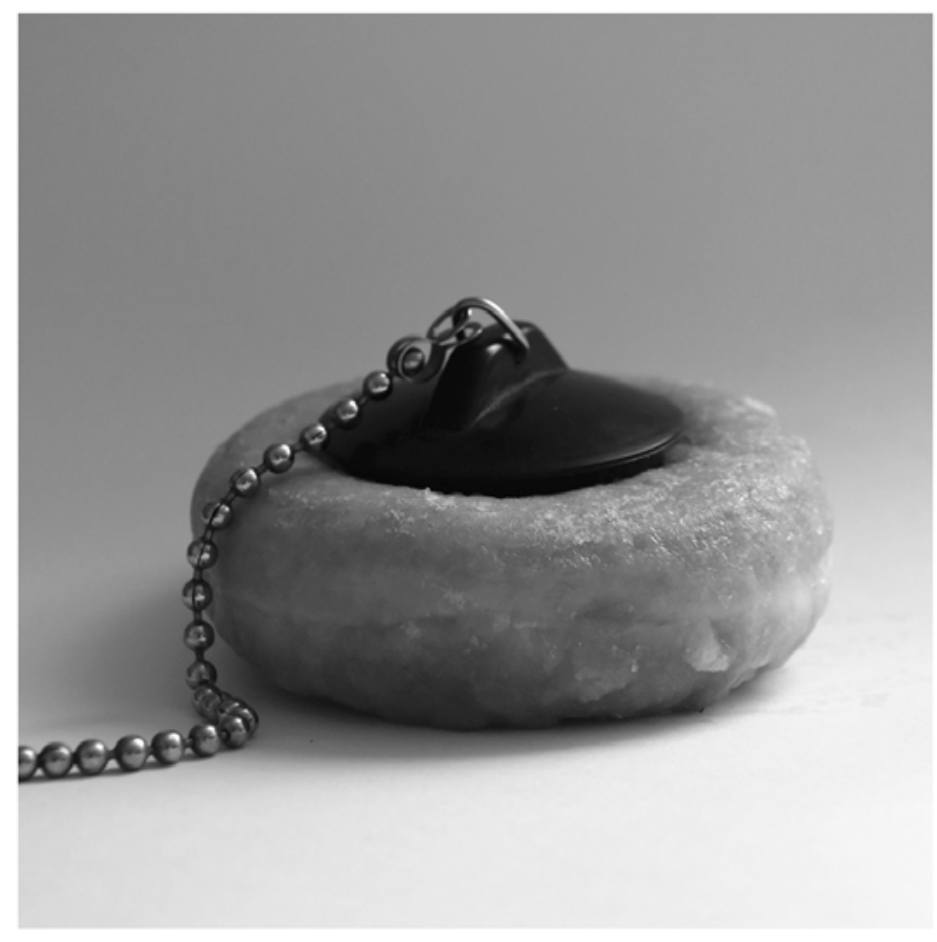

Rocio Villalonga. Tapón. 2016. Fotografía. 
www.terciocreciente.com
Investigación
Podríamos sintetizar las Conclusiones más relevantes en estos puntos:

_A la hora de desarrollar la obra gráfica en un inicio, nos preocupábamos por la forma del propio objeto, recurriendo pues a su análisis sintáctico. A medida que avan-zábamos ya en esos aspectos externos comenzamos a interesarnos en sus aspectos se-mánticos: La pérdida de significación ha sido uno de nuestros objetivos clave.
_Había que despojar al objeto de lo que semánticamente lo define. Una vez lo-grado todo ello recurrimos a preocuparnos por el intérprete, se trataba de algo mucho más dinámico y azaroso, ya que sometidas las obras (ilustraciones, tipografías, fotogra-fías, collages y fotomontajes) a distintas opiniones las lecturas eran múltiples, de modo que percibimos que era necesario el empleo de cierto método pragmático, para lograr un diálogo adecuado con el receptor de ese mensaje.

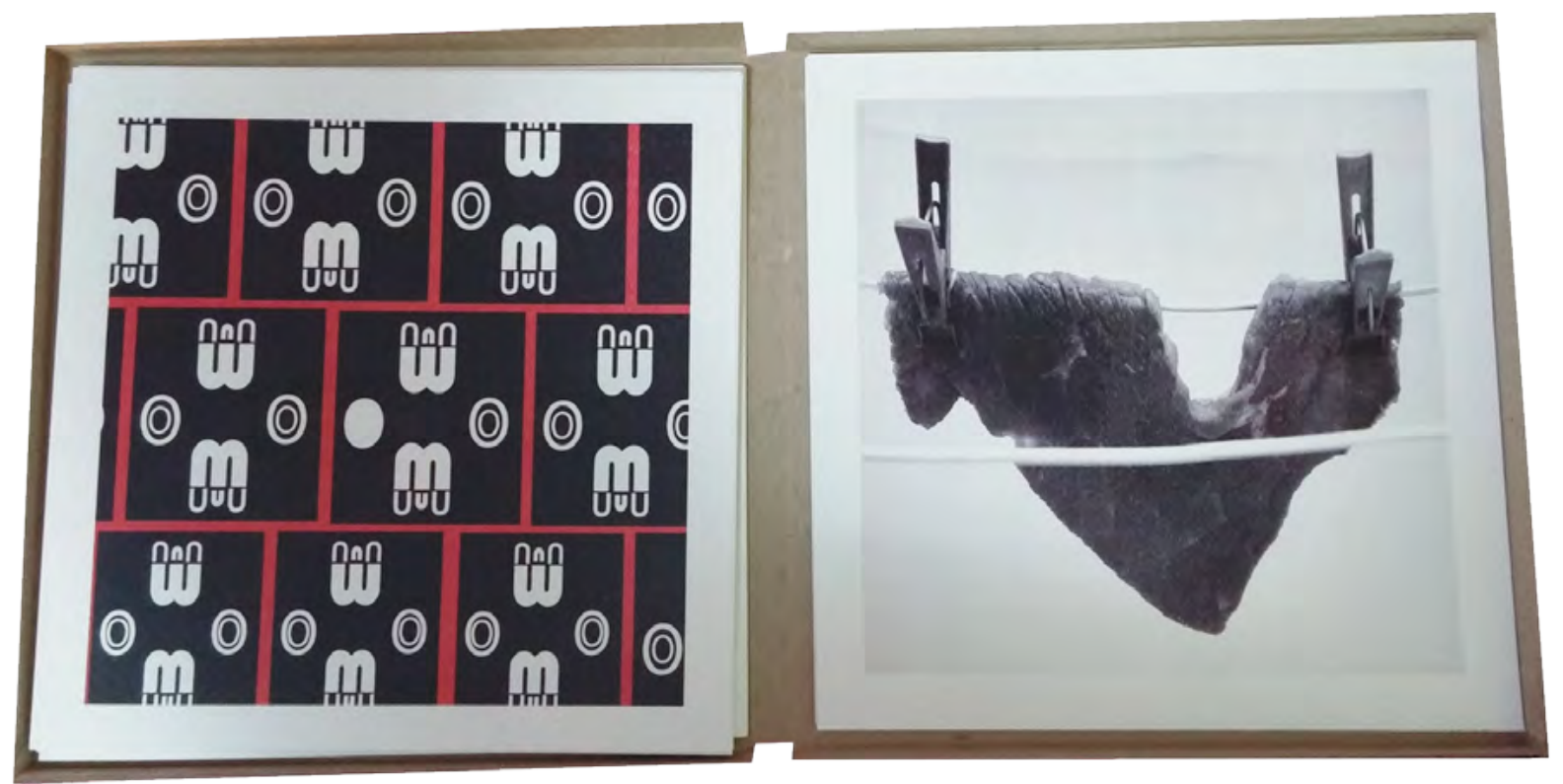

Así llegamos a concluir y cerramos el ciclo seleccionando la obra gráfica refe-rente a cada objeto, atendiendo a razones como: pérdida de significación y fragmentali-dad, en las que el collage analógico fue el punto de partida y la digitalización su repro-ductibilidad técnica y su serialización.

_Enfatizar la idea de fragmentalidad y multiplicidad nos ha permitido decons-truir el mundo "real" bajo el cual uno observa los objetos. La posibilidad de disponer de los objetos aisladamente, ha significado una tremenda fuente de inspiración para poder generar una obra que quebranta la apariencia, la significación, y los valores de utilidad de los mismos, posibilitando elaborar nuevos discursos escondidos en ellos, a partir de la modificación de los significantes no explicitados en la nomenclatura de los propios objetos. 


\section{Agradecimientos}

Agradecemos a Librodeartista.info Ediciones y al Departamento de Dibujo de la Facultad de Bellas Artes. Universitat Politècnica de València, organismos financiadores de la Convocatoria Internacional Libros de Artista Memorial Emilio Sdun y, en concreto, a los miembro del Comité Organizador: Antonio Damián, Antonio Alcaraz, Jim Lorena, José Gallardo, Antonio Gómez, José Emilio Antón por haber seleccionado nuestro pro-yecto

para participar en la convocatoria, lo que ha hecho posible la publicación de este artículo.

\section{Referencias}

Aliaga, J.V. (2001). Claude Cahun. Valencia. Catálogo exposición IVAM. [12]

Ammann, J.C. et altri. (1989). Meret Oppenheim. Defiance in the face of freedom. Zurich-Frankfurt-New York: Parkett Plubishers Inc. [13]

Andrews, I. (1994). Objet to be Destroyed: an excess of interpretation. Recuperado de http://ian-andrews.org/texts/object.html [14]

Bataille, G. (1984). Historia del Ojo. Barcelona: La Sonrisa Vertical. [3]

Benjamin, W. (2003). La obra de arte en la época de su reproductibilidad técnica. México, D.F.: Itaca. [2] Y [6]

Cifre, P. (2003). De la autoconciencia moderna a la metaficción postmoderna. Tesis doctoral. Universidad de Salamanca. Salamanca. [7]

Coleman, C. Madoz. (1999). Objetos 1990-1999. Catálogo exposición Chema Madoz. Madrid: Museo Nacional Centro de Arte Reina Sofía. [8]

De Diego, E. (1995). Los cuerpos perdidos. Fotografía y surrealistas. Barcelona: Catálogo ex-posición Fundación la Caixa. [9]

De Michelli, M. (2006). Las vanguardias artísticas del siglo XX. Madrid: Alianza Editorial. [4]

Greil, M. (2005). Rastros de carmín: una historia secreta del siglo XX. Barcelona: Anagrama. [11] 
Investigación

Hudson, M. (2014). Telegraph. Reino Unido. Hanna Hoch: The woman that history forgot. Recuperado de http://www.telegraph.co.uk/culture/art/10545071/Hannah-Hoch-Thewoman-that-art-history-forgot.html [10]

Santibañez, D. (1997). Investigación Social y Autorreferencia. Sistemas sociales y sistemas psíquicos como sistemas autorreferenciales. Cinta moebio 2: 114-128. Recuperado de www.moebio.uchile.cl/02/frprin05.htm

Stangos, N. (2004). Conceptos de Arte Moderno. Madrid: Alianza Editorial. [5]

Tzara, T. (1994). 7 Manifiestos Dada. Barcelona: Tusquets. Cuadernos ínfimos 33. $6^{\text {a }}$ edición. [1] 
Revista de Estudios en Sociedad, Artes y Gestión Cultural

www.terciocreciente.com

http://revistaselectronicas.ujaen.es/index.php/RTC
Monográfico Extraordinario I

Julio 2017

Investigación
ISSN: 2340-9096

DOI: 10.17561/rtc.mextra1.7 